\title{
Analysis of survival data from trials with non- proportional hazards: an empirical comparison of methods
}

\author{
Patrick Royston, Yinghui Wei , Jayne Tierney, Mahesh Parmar \\ From 2nd Clinical Trials Methodology Conference: Methodology Matters \\ Edinburgh, UK. 18-19 November 2013
}

\section{Introduction}

Non-proportional hazards are increasingly observed in publications of large trials. However, to use or not to use a method accounting for non-proportional hazards may be a difficult decision, in the absence of appraisals of existing methods and the uncertainty in whether results provide different or more insights into the clinical questions.

\section{Methods}

We analyse survival data reconstructed from two trials publications which reported extreme non-proportional hazards (with respective p-values as 9.19E-13 and $1.344 \mathrm{E}-24$ in non-PH Grambsch-Thernau test). We use the Cox proportional hazards model, flexible parametric model and accelerated failure time model to estimate the time-independent hazard ratio, between-arm difference in restricted mean survival time (RMST) and acceleration factor as respective summary treatment effect measures. Estimation of the latter two measures does not require $\mathrm{PH}$. We also analyse the hazard ratio and difference in RMST as time-dependent effects.

\section{Results}

In this empirical study, the three summary measures produce broadly similar results on the evidence against the null hypothesis. Both the Cox model and the flexible model are able to incorporate time-dependent treatment effects to account for non-proportional hazards. Flexible parametric models support plotting of the time-dependent hazard ratio and time-dependent difference in RMST, which provides useful insights into how the treatment effect measure may change with time.

MRC Clinical Trials Unit Hub for Trials Methodology Research, London, UK

\section{Conclusions}

Although p-values for the three summary measures have similar influence on the statistical significance of treatment effects, using the difference in RMST as the summary measure emphasizes the often-neglected time-horizon and allows more intuitive interpretation of the magnitude of treatment effects.

Published: 29 November 2013

doi:10.1186/1745-6215-14-S1-038

Cite this article as: Royston et al:: Analysis of survival data from trials with non-proportional hazards: an empirical comparison of methods. Trials 2013 14(Suppl 1):038.
Submit your next manuscript to BioMed Central and take full advantage of:

- Convenient online submission

- Thorough peer review

- No space constraints or color figure charges

- Immediate publication on acceptance

- Inclusion in PubMed, CAS, Scopus and Google Scholar

- Research which is freely available for redistribution
() Biomed Central 